\title{
A CONQUISTA DO ESPAÇO VARIAÇÃO SOBRE UMA ARTE DO ENCONTRO: O GESTO BARROCO ${ }^{1}$
}

\author{
Yannick Butel \\ Professor em Artes Cênicas na Aix-Marseille Université, Laboratório de estudos em ciências das artes \\ yannick.butel@sfr.fr
}

Tradução: Evelise Mendes

Doutoranda em Artes Cênicas, co-tutela entre UFRGS e Aix-Marseille Université eve.fmendes@hotmail.com

Se esse artigo tem um ponto de vista crítico, é porque ele foca nas finalidades e objetivos das práticas teatrais que, sob uma conjuntura ideológico-econômica, cientes ou não disso, se encontram a serviço do interesse e da preocupação do "fazer comunidade". Isso se dá em razão da organização estrutural do teatro (tanto os elementos teatrais quando a indústria do espetáculo) que faz parte de uma ideia de "fábrica do comum", onde é preferível a noção de público (e consequentemente de povo) à noção de indivíduo (ou seja, de singularidade banal, anônima). Em vista de tal organização estratégica do fenômeno teatral, as práticas em espaços abertos podem, então, ser consideradas como uma alternativa que incorpora o modelo de "biopolítica", cujo objetivo é o de libertar a vida, de retirá-la do adestramento institucional comentado por Michel Foucault em "A vontade do saber", quando ele analisa o "biopoder".

Palavras-chave

Colonização do pensamento. Práticas Urbanas. Espaço Público. Indústria Cultural. Teatro.
If this article has a critical point of view, it is because it focuses on the goals and objectives of theatrical practices that, in an ideological-economic context, are at the service of the interest of "community-making". This is due to the structural organization of the theater (both theatrical elements and the entertainment industry) which is part of the idea of "common factory", where the notion of the public (and consequently of the people) is preferred to the notion of individual (ie banal, anonymous singularity). In view of such strategical organization of the theatrical phenomenon, practices in open spaces can then be considered as an alternative that incorporates the model of "biopolitics", whose objective is to free life, to withdraw it from the institutional training commented by Michel Foucault in "The Will to Know", when he analyzes "biopower".

Keywords

Colonization of Thought. Urban Practices. Public Space. Cultural Industry. Theater.

1 Gostaria de agradecer imensamente à Evelise Mendes, pela tradução e leitura crítica desse artigo. 
O espaço é formado por um conjunto indissociável, solidário e também contraditório, de sistema de objetos e sistemas de ações, "[...] quadro único no qual a história se dá [...]" (Santos, 1997, p. 44).

Uma imensa parte da população é atualmente privada de toda experiência estética, o que a torna inteiramente submissa ao condicionamento estético (Stiegler, 2004, p. 20-21).

A produção capitalista unificou o espaço, que não é mais limitado por sociedades exteriores. Esta unificação é, ao mesmo tempo, um processo extensivo e intensivo de banalização (Debord, 1992, p. 129).

O caráter geral do mundo é o de ser caos por toda eternidade, em razão [...] da ausência de ordem (Nietzsche, 1982, p. 138).

A versão cinematográfica de Palitzsch ${ }^{1}$ para uma das mais importantes peças de Bertolt Brecht, Mãe coragem e seus filhos, a qual foi escrita em 1939 - Brecht se encontrava em exílio nos Estados Unidos naquele momento - e encenada em 1949, nos apresenta como imagem inicial algumas gravuras de guerra: dentre elas, cenas de batalha, de enforcados suspensos em árvores, de fossas humanas. Em seguida, aparecem os filhos de Anna Fierling, Eilif e Schweizerkas, empurrando a carroça ao longo de uma estrada repleta de árvores mortas, numa paisagem desértica...

Na última peça de Thomas Bernhard Praça dos Heróis ${ }^{2}$, apresentada no Festival de Avignon 2016 através da encenação de Krystian Lupa $^{3}$, a senhora Schuster se encontra num

\footnotetext{
1 Peter Palitzsch dirigiu o filme em 1960, contando com a participação dos atores do Berliner Ensemble.

2 Escrita em 1988, seu título original é Heldenplatz.

3 Espetáculo originalmente criado em 2015 no teatro nacional
}

típico apartamento burguês de Viena. Atrás dela, uma imensa janela iluminada pelo sol cuja vista é a praça onde, cinqüenta anos antes - em 1938 -, o então chanceler Hitler havia sido aclamado pela multidão em virtude da anexação da Áustria pela Alemanha. O professor Schuster acaba de se suicidar. O clamor da multidão é ainda audível.

Em Soubresaut ${ }^{4}$, última criação de François Tanguy, há uma fusão entre os poemas e textos de Celan, Dante, Kafka, Coleridge ditos pelos atores ao barulho dos bombardeios aéreos da Segunda Guerra Mundial, o qual é possível de se escutar de longe... O volume dos bombardeios é relativamente forte, ameaçando assim a harmonia musical e literária ditada pelo ritmo das frases lapidadas...

\section{Da "comunidade sensível"}

Não pretendemos aqui examinar esses três exemplos com vistas a satisfazer uma busca por interpretação, nem temos como propósito tecer análises minuciosas que levariam a uma elucidação do significado das respectivas criações. Através dessas três encenações, trataremos principalmente de desenvolver uma reflexão sobre a questão do espaço no processo teatral, considerando a citação de Milton Santos que se encontra na epígrafe desse artigo. Mais precisamente, nosso intuito é o de mostrar a partir de onde se dá a estreita ligação entre a complexa constituição espacial nos processos teatrais (assim como seus elemen-

da Lituânia, em Vilnius.

4 Espetáculo criado no Théâtre National em Bretagne dentro do festival Mettre en scène. Foi apresentado posteriormente em dezembro de 2016 no Théâtre du Radeau-La Fonderie, em Mans. 
tos constitutivos) e a escrita da História. A menos que se esvazie a História de seu conteúdo, na realidade trata-se de um ponto de vista que tem como fio condutor a relação entre política e estética ${ }^{5}$.

A priori, nossa abordagem não possui qualquer originalidade, já que há muito tempo que "Teatro, História, Estética e Política" possuem uma ligação inseparável.

Em vista disso, por que insistimos nesta questão?

Isto se faz necessário porque as pesquisas na área cenográfica ${ }^{6}$, como aquelas que relacionam o Teatro, a História, a Estética e o Político, não cessam de evocar uma invariante estrutura que torna o espaço teatral um "espaço

5 A singularidade $d a$ arte é de levar a uma redivisão do espaço material e simbólico. E é por isso que a arte toca o político. A política, de fato, não é o exercício do poder e a luta pelo poder. É a configuração de um espaço específico, o recorte de uma esfera particular de experiência, de objetos postos como comuns e tomado por uma decisão comum [...] (Rancière, 2004, p. 37). Insistimos sobre o detalhe dessa situação, a qual conecta estética e político ao espaço. Vem daí nosso interesse em citá-lo.

6 Dentre essas pesquisas, há aquelas empreendidas por cenógrafos de olhar crítico em relação ao espaço como, por exemplo, os cenógrafos dos anos 1960-70 pertencentes à Arte Povera (cujos questionamentos sobre o espaço e o fenômeno teatral os levou a intervir no meio urbano). Como explicou Jannis Kounellis, integrante do referido movimento: "Para começar, não vou ao teatro. Por que ir ao teatro se tudo está previsto ou é previsível, e se o antigo ainda prevalece de tal modo sobre o novo? Um artista evita isso, mas se ele decide fazer algo, ele só pode adotar uma atitude polêmica em relação ao que é o teatro, a essa máscara tomada de idéias esclerosadas que se esquivam de toda mudança [...] minha matéria-prima reivindica um espaço próprio, e ao mesmo tempo cria um espaço complexo que tende mais a colocar em questão a ficção no espaço teatral, a provocá-la, a revelar as forças implicadas, que fazer esquecê-la" (In "Après la scénographie", entretien dirigé par Guido Boursier, Italo Moscati et Marisa Rusconi, in Sipario, $n^{\circ} 276$, avril 1969). Poderíamos acrescentar ainda as experiências do Festival de Nancy, a apresentação do Living Theater no Festival de Avignon, a do Magic Circus no Festival Sigma de Bordeaux, a de Jean-Jacques Lebel, os happenings do Palais des Merveilles, o trabalho no espaço urbano do Théâtre de l'Unité de Jacques Livchine, etc., que se deram no espaço aberto e que foram tidas como um teatro de agitação urbana. à parte", uma entidade "separada"7 - tal como fora apontado criticamente por Guy Debord. Nesse sentido, refere-se a uma posição por meio da qual a alteração da perspectiva (o que estabelece a ficção, a arte) nos permitira de ver o que não vemos habitualmente, de compreender o que não compreendemos, de legitimar o que não legitimamos, os quais são, sem dúvida, aspectos próprios à técnica e prática artística. Embora tal invariante constitua o teatro como arte plena, paradoxalmente o mantém à margem da aparente realidade - diga-se de passagem, realidade um tanto míope, já que o que é percebido no teatro não é perceptível em outro lugar.

Através de inúmeros procedimentos que evidenciam uma perspicácia impressionante e um senso estratégico relativos ao modo como a ficção se apresenta e ao que ela ressalta, amplifica... O teatro é, portanto, o lugar onde podemos ver/de onde podemos ver. Até mesmo o dispositivo de visibilidade que se preocupa com o lugar do espectador - pois este deve enxergar -, tudo foi pensado pelo viés óptico que acoberta o jogo sensível.

Aliás, no que tange às considerações de cunho político proferidas até mesmo pela comunidade artística, poderíamos seguir disseminando essa lógica absurda, de superioridade irreal, a partir da qual somos levados a considerar uma imagem da mesma maneira que se considera um som poético como original: quando de fato, a realidade do mundo - esse espaço mofado - só foi transformada

\footnotetext{
7 O espetáculo se apresenta ao mesmo tempo como a própria sociedade, como uma parte da sociedade, e como instrumento de unificação. Enquanto parte da sociedade, ele é expressamente o setor que concentra todo o olhar e toda a consciência. Em virtude deste setor ser separado, ele é o lugar do olhar iludido e da falsa consciência; e a unificação que realiza não é outra coisa senão uma linguagem oficial da separação generalizada (Debord, 1992, p. 4).
} 
numa cópia rascunhada. ${ }^{8}$

Um exemplo é a "reflexão política" que Malraux fez sobre arte durante sua viagem ao Rio de Janeiro (chamando o Brasil de "país da esperança"), após a Brasília ("esta Brasília, sobre planalto colossal, é como a Acrópole sobre seu rochedo..."), antes de estudar na faculdade de filosofia em São Paulo. Não parando de discorrer sobre clássicos como Sófocles, Corneille, Shakespeare, entre outros, sua viagem politizada a São Paulo em 26 de agosto de 1959 é pontuada por um discurso em que concebe a arte como revelador da dignidade humana.

Há também as "reflexões estéticas", onde intelectuais do teatro teorizam sobre o trabaIho dos dramaturgos - como o que fez Bernard Dort a respeito de Bertolt Brecht :

seu teatro épico aparece assim como uma tentativa de descondicionamento e de destruição das ideologias. Levando para a cena os mitos da vida cotidiana, nosso modo de viver a História dia após dia, até mesmo um tanto da teatralidade que há nesta vida rotineira (nossos gestos e opiniões...), Brecht nos oferece um modo de tomar distância e de nos libertar dessas questões do cotidiano. A matéria desse tipo de teatro são as falsas representações que o homem faz de si mesmo e da sociedade (Dort, 1960, p. 199).
8 Tal constatação é o alvo da crítica de Debord. Citando Feuerbach: "E sem dúvida o nosso tempo... prefere a imagem à coisa, a cópia ao original, a representação à realidade, a aparência ao ser... O que é sagrado para ele, não passa de ilusão, mas o que é profano é a verdade" (Debord, 1992, p. 132). A análise de Debord salienta essa confusão, notando que há uma intenção e uma vontade de poder de mantê-la: "O espetáculo, compreendido na sua totalidade, é simultaneamente o resultado e o projeto de mundo da produção existente. Ele não é um complemento do mundo real, um adereço decorativo. Ele é coração da irrealidade da sociedade real. Sob todas suas formas de informação ou propaganda, publicidade ou consumo direto de diversões, o espetáculo constitui o modelo presente da vida socialmente dominante" (Debord, 1992, p. 5).
Seria possível reproduzirmos inúmeros desses discursos sobre arte, especialmente do teatro atribuído como "sendo popular" e ao "serviço de".

"Revelar, reconhecer, despertar, desmistificar, educar..." Fica evidente que nessa perspectiva de utilidade da arte teatral, ela é considerada como um espelho mágico que permitiria ver o que estava escondido. Isto é, diz respeito à característica de uma arte que estaria a serviço da veracidade, devendo nos afastar "das falsas representações", como o que escreveu Dort a respeito do trabalho de Brecht, tendo um caráter "revelador", segundo Malraux.

Mas como não desconfiarmos dessa aliança entre o político e o teórico? Como não nos intrigarmos com esse acordo que acaba influenciando a finalidade do espaço teatral? Como não nos incomodarmos com tamanha ligação e pacto? Precisamos dar razão a Bernard Stiegler:

a questão política é essencialmente
a questão da relação ao outro, de um
sentir em conjunto [...]. A política é a
arte de garantir uma unidade da cité,
particularmente do seu horizonte em
comum [...]. Então tal objetivo supõe
uma essência estética em comum. O
estar junto se refere a um agrupamen-
to sensível. Por isso, uma comunidade
política é a comunidade de um sentir
(Stiegler , 2004, p.18-19).

Nesse sentido, indivíduos da área da teoria e da política, assim como os artistas, tendem a trabalhar com o objetivo de estabelecer uma "comunidade sensível" reunida, em suma, em torno de uma cultura. Em outras palavras, prevalece uma ordem estética que se confunde à ordem política, cuja finalidade é a de controlar o espaço através da cultura - a qual se espalha. 
Assim sendo, voltando à questão motivadora de nossa análise, a separação entre os espaços (espaços de ficção/ espaços de realidade) se legitima através de um princípio político responsável por conservar uma dualidade. Esta, por sua vez, forma uma unidade conhecida também por "comunidade sensível". Ao manter a arte teatral nessa configuração, ela se torna uma arte com função de revelar, de desvendar, onde o "sentir" é o sintoma da comunidade; o "sentir a si mesmo", como comentou Jean-François Lyotard, é obtido por meio do princípio da permuta que rege a relação entre o espectador e o objeto artístico.

Efetivamente, o teatro é uma arte alética (do grego alêthês, quer dizer "de essência verdadeira"). Ele se caracteriza por ser um espaço que se propõe a refletir, corrigir e ampliar essa sociedade imperfeita, dando assim uma densidade que lhe falta. Isso resulta numa série de equívocos, como: o de confundir a cópia com a realidade, o de enganar-se sobre a relação do original e de sua representação, o de preferir o modelo resultante a sua matriz, o de privilegiar a imagem do espelho em detrimento das feições do mundo, o de emocionar-se com a ficção - quando a realidade lhe é indiferente...

Enfim, o espaço teatral tem sido pensado e legitimado por meio da cisão entre os espaços (o que já relatamos anteriormente). Isso faz com que ele possa se assemelhar, em termos de modo de funcionamento e de finalidades, à lógica lacaniana de se reconhecer frente a um espelho.

Mas o que aconteceria com tal cisão dos espaços se a arte teatral se libertasse desse controle ideológico? E se a prática do teatro se desprendesse da pressão sistemática da comunidade sensível? Caso os efeitos da co- lonização do pensamento ${ }^{9}$ no teatro fossem levados em conta, eles viriam a se reduzir ou a desaparecer? O que seria de uma prática teatral ou artística que não estivesse mais ao serviço da cultura - a qual, diga-se de passagem, representa somente uma ordem estético-política?

A priori, nossas problematizações não parecem ser convenientes, uma vez que elas entram em conflito com uma concepção de teatro que, ao longo dos séculos, desde A Poética de Aristóteles ao Teatro pós-dramático de Lehmann - o qual assinala o "desencanto pós-moderno", bem como o luto da comunidade -, propõe somente derivações da idéia de "partilha do sensível".

Sendo assim, arrisquemo-nos no desenvolvimento de nossa hipótese.

\section{O Eco e o ponto de apoio}

Convocando esses três exemplos de encenações, tentaremos refletir sobre a questão do espaço de outro modo. Então, voltemos a eles.

Em Mãe Coragem e seus Filhos, de Brecht, diversas gravuras de relação mimética à Guerra dos Trinta Anos são mostradas logo no início, servindo como testemunhas históricas, imagens "fotográficas". Em consequência, por se tratarem de obras pictóricas, ou seja, de matéria artística, elas remetem à função do arquivo e o problematizam.

Em Praça dos Heróis, o olhar da viúva Schus-

9 A expressão "colonização do pensamento" é uma maneira de denominarmos as invariantes estruturais da arte teatral: comunidade reunida, prática artística calcada na comunicação, espaço de partilha das sensações, jogo dialético entre realidade/ficção, divisão do espaço, etc. Complementamos ainda que a teorização das formas contemporâneas (as quais deslocam em parte essas invariantes) se baseia na dissolução e desconstrução delas. 
ter, a qual está posicionada atrás da janela do apartamento que paira sobre a praça histórica, é sem direção. Ela nada vê, mais ela ainda pode ouvir os clamores vibrantes da multidão de 1938. O arquivo sonoro e histórico contribui na atualização desse fato que ocorreu há mais de cinqüenta anos. Toda seqüência temporal é um equívoco. Nenhuma imagem é produzida, mas a imagem acústica estabelece a co-presença entre os diferentes tempos da História.

Em Soubresaut, o espaço cênico que se encontra parcialmente em canteiro de obras, desconstruído, pulverizado, num caos que alimenta o incessante desequilíbrio físico e vocal do elenco, faz espalhar sons de bombardeios longínquos. Tais barulhos, distintos mas não incômodos, se misturam às movimentações sinfônicas de percussão... Isso até o ponto que a união entre eles forma uma combinação imprevista, um som inesperado e insólito, pronto a nos lembrar das experiências sonoras de "música concreta".

De pronto, esses três exemplos nos conduzem a dois tipos de reflexões.

A princípio, e numa relação despretensiosa ao que foi proposto pela representação, é sempre possível de notarmos nessas imagens - visuais e acústicas - um conjunto de fatores que estrutura a ficção como um espaço de duplicação do mundo exterior. Trata-se de um efeito de espelho (podemos chamá-lo assim), onde a imagem e o som se espalham no espaço teatral tal qual um eco, cuja origem se deu em um tempo e lugar anteriores ao da representação (ou seja, com uma origem situada na História).

Como todo "eco", ele nos chega sob forma um tanto diferente do seu original, embora seja possível de perceber qual é a sua fonte. Isso porque é próprio do trabalho poético, plástico e estético de fazê-lo se parecer e se diferenciar instantaneamente a sua matriz. E é através dessa distinção que o original pode ser observado diferentemente. Todo trabalho teatral que se apóia em tal prática de semelhança e de diferença concebe o espaço teatral como um espelho, por meio do qual o princípio de reconhecimento permite um melhor conhecimento sobre o original.

Mediante os arquivos e documentos históricos, como as imagens da Guerra dos Trinta Anos (num recurso de parábola tipicamente brechtiano), o registro dos clamores da multidão em 1938 na Praça dos Heróis, a trilha sonora de bombardeios em Soubresaut... O espaço teatral, assim, estabelece uma relação dialética entre dentro e fora, um espaçamento entre modelo referencial e modelo derivado. Dessa forma, imagens sonoras e visuais favorecem uma ligação óptica ao que foi apresentado.

Dito de outra maneira, podemos identificar o que vemos/escutamos sobre a cena via a memória que temos do externo. Por conseguinte, o trabalho teatral conduz a uma atualização e a uma estética de cunho testemunhal, onde os motivos comportamentais (de caráter afetivo, de memória, de sociedade) apresentados em cena, tal qual um divã, convocam as reminiscências.

No entanto, sob outro ponto de vista, se o espaço teatral é, em parte, o lugar da convocação, a complexidade plástica do fenômeno teatral não deixa de produzir pontos de resistência. O tempo da representação bem como sua estrutura não fazem parte unicamente de um teatro epifilogenético - como se fosse um "repositório de memória" (Stiegler, 2004, p. 77) -, mas também de uma experiência estética da qual participa o indivíduo. Em outras palavras, 
tal experiência pode ser explicada por meio da função háptica (força secundária da óptica), a qual é colocada em movimento ao mesmo momento que a função óptica (ver/reconhecer/lembrar-se). Por função háptica, entendemos como uma "possibilidade do olhar" que, longe de depender e de ser interrompida pela matéria visual, tão somente a atravessa com o objetivo de alcançar o espaço tátil. Efetiva-se, dessa forma, um mundo de impressões e armazém de sensações responsável por remeter o espaço material para a pele - pele que envolve e abriga um espaço não-materializado, não-referenciado. Assim, passamos do "ver" (estética da recepção) ao "dar à vista" (fenomenologia da percepção).

Em virtude disso, a potência do fenômeno teatral reside no fato de ele ser, simultaneamente, espaço de convocação e espaço de transmissão ou de conexão. Se o teatro se assemelha a um espaço que duplica o modelo referencial, ele funciona também como um "ponto de apoio" e uma "linha de fuga" para aquele que se encontra em situação de espectador. Ou ainda, a partir da ideia de Gilles Deleuze a respeito da atividade do pensamento, consiste numa "linha feiticeira" (Deleuze, 1990, p. 141).

Olhando as gravuras da Guerra dos Trinta Anos em Mãe Coragem, escutando o arquivo sonoro dos clamores de 1938 em Praça dos Heróis, reconhecendo o som de bombardeio na faixa sonora de cunho documental em Soubresaut... Tudo isso pode nos levar a pensar sobre o sentido e o significado desses três recursos nos respectivos processos de criação, bem como sobre seus efeitos no nosso entendimento de História. Do mesmo modo, tais elementos são capazes de nos conduzir a uma reflexão a respeito da natureza desses gestos teatrais e de sua categorização (se são realistas, naturalistas, documentários...).

Ainda assim (de modo um tanto arriscado, mas nem por isso menos pertinente), podemos repensar a questão da prática teatral numa perspectiva de 'deslizamento' da atividade óptica em direção à háptica. Isto porque, do ponto de vista estrutural, o teatro sempre manteve pontos de contato, zonas fronteiriças e territórios de intimidade com aquilo que ultrapassa o teatro e que se chama vida...

Em vista disso, longe de significar um final, a experiência estética é somente uma etapa necessária ou uma passagem que integra um formato mais denso do tempo e do espaço formato este propício para a experiência do pensamento de si/sobre si. Tempo e espaço que, mesmo sendo simultâneos à representação, não pertencem a ela, já que deles brotam uma abertura (como uma brecha) a partir da qual é possível sentir a palpitação da vida. Nesse espaço-tempo, efetiva-se uma hermenêutica do indivíduo que, por sua vez, se prende a um processo de subjetivação ${ }^{10}$ singular da experiência ${ }^{11}$ intensa.

Em razão disso tudo, nos parece que no fenômeno teatral - onde se contrapõe "cultura de si" à "economia da cultura"12 - reside uma questão que tende a emancipá-lo da mira da ordem estético-política dominante, ordem que, diga-se de passagem, não leva em conta

10 Isto é, a descoberta de um pensamento, de algo impensado que tem a ver com "[...] a constituição de modos de existência [...] a invenção de novas possibilidades" (Deleuze, 1990, p. 131).

11 O que é exatamente o pensamento. A propósito disso: "Pensar é sempre experimentar, não interpretar, mas experimentar, a experimentação é sempre atual, o nascente, o novo, o que está em processo de se fazer [...]" (Deleuze, 1990, p. 144).

12 Lembremos da relação entre "economia da cultura" e "comunidade sensível"... 
a dimensão da hermenêutica do indivíduo. Salientamos que, no entanto, as práticas teatrais urbanas ocorridas nos espaços públicos abertos são um horizonte para tal hermenêutica, são uma possibilidade para que essas novas conexões rompam com questões já denunciadas por Horkheimer e Adorno nos anos 1930, como com "a padronização e a produção em série" (Horkheimer; Adorno, 1974, p. 130), com "o empobrecimento dos materiais estéticos" (Ibid., p. 133), com a organização do mercado de oferta e demanda - responsável por estimular os mecanismos entre espectador e espetáculo, bem como pelas expectativas do sistema social em detrimento da obra artística e do indivíduo. Em suma, tais práticas representam aqui uma ruptura com a "indústria cultural" que "não sublima, mas reprime" (Ibid., p. 148), responsável por produzir "sem parar novos efeitos que permanecem conforme o antigo modelo, [e que] serve unicamente para ampliar o poder das convenções" (Ibid., p. 137).

\section{Ordem pública versus prática "selvagem"}

Antes de prosseguirmos em nossa reflexão, é necessário esclarecermos uma questão, visto que é possível darmos a entender que nosso intuito é o de construirmos uma crítica em que se oponham dois tipos de práticas teatrais - aprovando-se ao final aquela que se desenvolve nos espaços abertos.

Não é nosso objetivo, de maneira alguma, fazermos um quadro explicativo do que o teatro deveria privilegiar ou não, de quais características seriam ou não desejáveis, do que seria justo e pertinente ou não. Não podemos adentrar a esse tipo de avaliação, até porque nossa análise não dá conta da multiplicidade das experiências teatrais.

As observações que fizemos até agora foram uma simples tentativa de definirmos uma tendência e uma linha de pensamento. Iniciamos problematizando o processo da reiteração de invariantes estruturais, os quais mantêm o espectador num "horizonte de expectativa" (termo utilizado por Paul Ricoeur), bem como o conduziriam a um processo de cultualização e de fetichização do fenômeno teatral. Em seguida, em virtude dos motivos já salientados, calcamos nosso raciocínio na ideia de que o projeto estético-político de "comunidade sensível" equivale a uma "conquista do público", o que em outros tempos era denominada de "doxa"13 (Lyotard, 2012, p. 176). Por fim, tínhamos chegado às reflexões sobre a "industrialização da cultura" (Horkheimer; Adorno, 1974; Jameson) e a "sociedade do espetáculo" (Debord, 1992), já que elas são praticamente impossíveis de serem ignoradas.

Se nosso ponto de vista é crítico, é porque temos como foco as práticas teatrais que, sob limitação e pertencentes a uma conjuntura ideológico-econômica ${ }^{14}$, se acobertando ou não nela, servem aos interesses do "formar uma comunidade". Considerando-as sob o viés estético, trata-se de práticas que se apóiam e favorecem mais o diálogo (sendo, a priori, dois espaços de enunciação, cena e público, que retomam a ideia de separação - já analisada - entre modelo referencial e seu derivado) que o solilóquio (o diálogo do espectador consigo

13 Ler o capítulo "Arraisonnement de l'art. Epockhè de la communication".

14 Significa que as estéticas teatrais, na sua diversidade e pluralidade, responderão consequentemente às determinações ideológicas que organizam a sociedade do espetáculo. Formulando de um modo lyotardiano, tratar-se-á de produzir obras "programáveis" que obedecem ao "programa" estético-político (Lyotard, 2012 p. 176). 
mesmo). Além disso, a organização estrutural do teatro (do mesmo modo que aquilo que constitui a indústria do espetáculo) integra um projeto de "fábrica do comum", onde se prefere a noção de público (ou seja, de povo) à noção de indivíduo (isto é, de singularidade banal, anônima).

Em relação a toda essa organização estratégica do fenômeno teatral, as práticas artísticas ocorridas nos espaços abertos são como uma alternativa.

Alternativa à uniformização e à instrumentalização da arte, alternativa e lugar de resistência aos modos de controle, alternativa aos espaços de confinamento que são, em geral, os edifícios teatrais, alternativa ao teatro de comunicação e de transmissão ${ }^{15}$, alternativa à industrialização do fenômeno e da linguagem teatral, alternativa à cenografia de cunho de revelação, de desvendamento (algo que é próprio ao espaço dialético cena/sala e suas variações), alternativa ao pragmatismo imposto pelos "intelectuais sentados", alternativa a uma sociedade do espetáculo perfeitamente organizada, alternativa à administração do fenômeno teatral, alternativa à alienação das práticas artísticas em relação ao modelo vigente de organização e legislação do trabalho, alternativa à produção em série, ao que está na moda, ao sistema de mercado e industrial, alternativa ao objetivo de se constituir primordialmente uma "comunidade sensível".

Finalmente, consiste numa materialização do modelo de "biopolítica" (Negri, 2002, p. 89), cujo objetivo de libertar a vida, de retirá-la do adestramento institucional, foi comentado por Michel Foucault em A Vontade de Saber -

15 A respeito das sociedades de controle, Gilles Deleuze ressaltou o fato que elas se apóiam na circulação da informação e da comunicação. Em virtude disso, uma sociedade de controle se funda na propagação de palavras de ordem. quando ele analisou o "biopoder".

Isto posto, é necessário explicarmos que o que tais alternativas colocam em jogo não se opõe ao que as práticas teatrais de espaços fechados criticam. Há inúmeras encenações e dispositivos teatrais, das mais diversas estéticas, que possuem claramente uma posição crítica e poética em relação ao mundo. Nesses casos, o mais importante não é a questão da emoção, do prazer, da intensidade como um sentimento vivo... Novamente, e insistimos nisso, não condenamos os artistas que fazem uso destes artifícios. No estilo de Georges Perec (que escreveu o livro Je me souviens), muitas delas mereceriam ser registradas num bloco de anotações por aqueles que a presenciaram, por seus espectadores-críticos, os quais começariam pela frase "Eu me lembro"...

Se podemos atribuir às práticas teatrais dos espaços abertos uma forma de resistência aos meios de controle (o que havíamos ressaltado anteriormente), podemos encará-las também, e principalmente, como um dinamizador e vetor de uma outra lógica de pensamento - a qual gera estéticas diversas ${ }^{16}$, e que concatena questões antropológicas e políticas. Isso é evidente, dado que os artistas teatrais dos espaços abertos estabelecem uma relação crítica e teórica para com o espaço, ou melhor, para com a organização espacial do Estado. Tal organização dissemina um modelo de sociedade através de seus movimentos, seus fluxos, suas zonas de controle, seus perímetros localizados e divididos, tendo seus territórios regidos pelo direito e pela lei que constituem o espaço público, acima de tudo, como um espaço pertencente à ordem pública.

Conforme Cornelius Castoriadis, a ordem

16 Poderíamos pensar em "formas performativas" para designar essas práticas ocorridas nos espaços abertos. 
pública faz parte de uma instituição imaginária da sociedade. Ela participa unicamente dessa escolha arbitrária que se funda na exclusão autoritária de outras possibilidades. Origina-se, principalmente, de um processo de agenciamento de cunho ideológico-econômico através do qual, enfim, uma apresentação ou exibição artística é vista como uma ordem estética que reflete a ordem política dominante.

Prosseguindo na nossa análise, faz-se necessário expormos as seguintes linhas de pensamento: a de Pierre Clastres, quando este lançou uma crítica afiada dirigida à organização dessa sociedade segmentada - "[...] toda sociedade dividida é uma sociedade servil [...]" (Clastres, 1974, p. 113) -; a de Guy Debord, o qual demonstrou desconfiança em relação à organização do espetáculo - "[...] o espetáculo é o discurso ininterrupto que a ordem vigente faz sobre si mesma, seu monólogo elogioso. É o auto-retrato do poder no momento da sua gestão totalitária das condições de existência [...]" (Debord, 1992, p. 12) -; a de Felix Guattari em que, se referindo aos territórios urbanos, suspeitava dos aparelhos que inundam o espaço - "A cidade é a estrutura que concentra os aparelhos que são, por sua vez, máquinas pertencentes ao socius. A cidade concentra ao máximo as máquinas do socius [...]" (Guattari apud Foucault, 2001, p. 1316) -; a de Gilles Deleuze que, se dirigindo a Michel Foucault, buscava mostrar a relação conflituosa da influência do Estado e do Poder sobre o "espaço público [que é] completamente desprezada pelo regime capitalista [...]" (Deleuze apud Foucault, ibid., p. 1323); a de Foucault que, respondendo à Deleuze, Ihe recorda que uma "relação de poder pressupõe a existência do equipamento coletivo e seu funcionamento" ( $p$. 1319), denunciando assim o caráter normativo do espaço público, cujo território não é mais de produção, mas sim de consumação padronizada ${ }^{17}$... Tudo isto nos leva a pensar que os "atores" das práticas artísticas nos espaços abertos estabelecem uma ligação diferente em meio a toda essa contaminação do espaço público pela lógica liberal, lógica que desenvolve um modo de produção seletivo e exclusivo e que só tende a favorecer uma demanda

A propósito, tal demanda satisfaz uma classe dominante através da exclusão da grande maioria, ocasionando, por sua vez, uma separação, uma divisão, até mesmo uma guetização em âmbito social. Desse modo, constitui-se um paradoxo que aparentemente não se vincula mais à esfera do poder pois, embora ele preconize a constituição de uma "comunidade sensível" ou demonstre uma preocupação com o Mit sein (em alemão, significa "estar junto"), de fato é o responsável por um efeito social no qual o Mit welt ("o mundo em comum") não passa de ilusão.

Numa conjuntura de sociedade de caráter liberal, da qual decorre divisão, saturação, segmentação, nomenclatura, sinalização, regulamentação, privatização do espaço... Diante do processo de "mundialização" (apontado por Henri Lefebvre em A Produção do Espaço) e de "compacidade"18 (assinalado por Miguel Abensour, consiste na perda física dos espa-

17 Ora, o desaparecimento dessa atividade produtiva (isto é, os espaços de invenção, de ação e de imaginação próprios ao indivíduo) em benefício do consumismo padronizado nos remete diretamente ao comentário de Guattari: "[...] a essência da cidade autoritária é a sua atividade de anti-produção [...]" (Guattari apud Foucault, 2001, p. 1317). Nessa mesma ideia que revela a proximidade entre economia liberal e sociedade de controle, Debord frisou que: "[...] o espetáculo é o momento em que a mercadoria ocupa totalmente a vida social [...]. A produção econômica estende sua ditadura extensiva e intensivamente [...]" (Debord, 1992, p. 25).

18 N. da T.: "Compacité" é uma palavra-conceito formulada por Abensour que designa simultaneamente condensação, concentração e saturação no espaço. 
ços disponíveis ou o excesso de espaços regimentados)... Em meio a tudo isso, as ações artísticas em espaços abertos, por equivalerem a energias diferenciadas que surgem ou interferem, são consideradas inevitavelmente como movimentações que fragilizam, contestam e desestabilizam um espaço ocupado e pensado, a priori, como legítimo, sancionado. Salientamos o "a priori" pois, como mencionou Jean-François Lyotard, o objetivo do sistema liberal é o de "destruir o que resta das culturas não-capitalistas" (Lyotard, 1994, p. 13). Apesar da aparente e frágil harmonia que rege as relações do corpo social, de acordo com Foucault trata-se somente de uma ilusão originada a partir dos modos de controle:

Penso que o grande fantasma é a idéia de um corpo social que seria constituído pela universalidade de vontades. Ora, não é o consenso que faz surgir o corpo social, mas sim a materialidade do poder sobre o próprio corpo dos indivíduos [...] (Foucault, 2001, p. 1622).

À medida que as manifestações artísticas em espaços abertos são comparáveis a um impulso vital (no sentido bergsoniano) e legítimo, elas são consideradas pelo Político como perturbações e "violências" feitas à ordem pública. Isso se dá em razão de o espaço urbano, segundo Lefebvre, ser o lugar para questões sociais que podem gerar tensões, tentativas de reapropriação e conflitos (mesmo estéticos). Dessa forma, ao invés de espetáculo, estas produções promovem uma espécie de tensionamento e de desafio à ordem estética, já que "[...] o espetáculo [...] é a representação diplomática da sociedade hierarquizada perante si mesma, em que qualquer outra palavra é banida [...]" (Debord, 1992, p. 11). Ainda assim, devemos frisar que nada do que é estabele- cido e privilegiado pelo Político, nem mesmo dentre as instituições dominantes e os modos de controle, é capaz de justificar a ordem. Georges Balandier trouxe à tona a única explicação lógica para tal fato: "a ordem e a desordem são como o verso e o reverso de uma moeda, isto é, são indissociáveis" (Balandier, 1988, p. 117). Quer dizer, formulando como René Char (1971), uma imprecisão entre "a base e o topo" instaura uma relação de convivência, de movimentação e, algumas vezes, de inversão nas representações, tal qual pode ter sido o caso de A América Invertida (1943), de Joaquin Torres Garcia.

No caso, as práticas artísticas feitas nos espaços abertos não são menos legítimas que aquelas que se encontram sob privilégio de uma ordem vigente, ordem que contribui ao que denominaríamos de "[...] banditismo das sociedades [...]" (Char, 1971, p. 31). Se elas se parecem a formas ameaçadoras e movimentos de insurreição social, se elas infringem o acordo estabelecido, se elas, ao dissolverem referências estabelecidas, demonstram o quanto o espaço público é controverso e lugar de conflito, equivalendo a pequenos tremores de terra, "[...] a fontes de calor sob a superfície fria da sociedade [...]" (Balandier, 1988, p. 74), a pontos de intensidade de uma vida que se desenvolve à margem da ordem... Por tudo isso, tais práticas são "[...] uma espécie de abalo sísmico [...]" (Debord, 1992, p. 11).

Sua maneira de reagir à ideologia dominante (cuja forma, de corpo social endurecido e domesticado, compreende as formas estéticas que ela difunde) se dá através da reintrodução de um gesto excluído, de um corpo físico e artístico. Aliás, esse gesto em nada se parece com uma reconquista ilegal do espaço, não há nada de antinatural nele pois, como Gilles 
Deleuze e Felix Guattari haviam dito a respeito dos espaços lisos e estriados, esses:

dois espaços só existem através das misturas entre si: o espaço liso não cessa de ser traduzido, convertido num espaço estriado; o espaço estriado é constantemente revertido, devolvido ao espaço liso [...] (Deleuze; Guattari, 1980 , p. 593) ${ }^{19}$.

Quando determinada prática artística alternativa se vê inesperadamente absorvida num processo de desregramento ou de desordem, ela se constitui como força legítima que vem a comprometer a ordem estética. Não se trata exatamente de uma desordem, mas sim de um movimento inerente à configuração do espaço da Polis a qual é, sem dúvida, ligada ao Polos $^{20}$. Com efeito, consiste apenas num exercício de "democracia selvagem" como diria Abensour; ou melhor, numa reintrodução de uma diversidade que favorece o surgimento de

19 Um dos capítulos do livro foca, dentre outros assuntos, na compreensão e na representação do espaço. Deleuze e Guattari definem o espaço estriado como um espaço ajustado, regido, ocupado, enquanto que o espaço liso é constituído por fronteiras e limites incertos. Eles desenvolvem a ideia de que ambos os espaços se encontram constantemente em estado de conflito, num movimento de fluxo e refluxo. Numa relação um tanto confrontativa, de energias e forças que se opõem, espaços lisos e estriados estabelecem um vínculo dialético através do qual o que estava sedentário, domesticado e enrijecido se aproxima fatalmente de um estado provisório, jamais definitivo, uma vez que o espaço é submetido simultaneamente ao nomadismo, ao que é selvagem, ao movimento. De certa maneira, por exemplo, o modelo democrático instalado e instituído via aparelho de Estado não está protegido do que Miguel Abensour denomina de "democracias selvagens", as quais consistem na reapropriação pela luta de um espaço conquistado e fechado (que pode se tornar novamente um horizonte aberto)

20 Polos e Polis derivam de politeia, que significa "arte de governar a cité". A ideia de Polis grega, a qual alimentou nossas representações de um modelo de desenvolvimento político e de organização do espaço público, é inseparável etimologicamente de Polos, que por sua vez se origina de Peleîn ("girar em torno de um eixo"). Assim, a Polis derivada de Polos redescobriria seu movimento que, conforme analisou Philippe Ivernel em Le Tournant esthétique, trata-se de um "redemoinho" - sendo por isso movimento. uma situação de diálogo necessária (espécie de Agora).

A propósito, devemos admitir a possibilidade de que a copresença de formas artísticas, algumas erguidas sobre a ordem estabelecida e outras sobre práticas alternativas em espaços abertos, entrem em concorrência. Assim sendo, validar a natureza competitiva desses espetáculos significa manter o paradigma da oferta e da demanda e, consequentemente, reforçar o pensamento de Guy Debord - quando ele analisa os desvios do espetacular, "[...] a raiz do espetáculo está no terreno da economia tornada abundante, e é de lá que vêm os frutos que tendem finalmente dominar o mercado espetacular [...]" (Debord, 1992, p. 11) ${ }^{21}$. No entanto, esse único comentário, que serve mais de constatação do que de análise, não é o bastante para esclarecermos o que está em jogo aqui.

Nossa problematização considera a escrita do espaço que se remete à da História; mais especificamente, se concentra na fusão entre gesto de escrita e gesto político. Se a ordem vigente e seus aparelhos constituem uma prática de escrita - o que alguns identificam como "um fluxo de escrita autoritária" (Guattari apud Foucault, 2001, p. 1316) -, as práticas artísticas dos espaços abertos são a tentativa política, e particularmente estética, de contrariar tal escrita - "esses falsos escritos", o que as levam a escreverem de outra maneira as relações tecidas no espaço. Antes de prosseguirmos, salientamos que a compreensão tanto das problemáticas espaciais como das questões ligadas à estrutura do espaço nos conduzem, de certa maneira, a uma reflexão sobre a escrita, a linguagem e seus epifenômenos. Em

21 A respeito da natureza desse fenômeno, Guy Debord reconheceu também uma "liberdade ditatorial do Mercado". 
vista disso, as práticas artísticas em espaços abertos podem ser identificadas numa resposta ao questionamento que Eduardo Galeano fez sobre o modelo de sociedade privilegiada na América do Sul: "O que a voz do sistema Ihes oferece? O sistema fala uma linguagem surrealista" (Galeano, 1981, p. 16).

\section{"A baixa linguagem"22}

O título acima pode parecer um tanto estranho. Desfaçamos, então, as zonas de ambiguidade que repousam nessa "expressão": aqui, ela não possui qualquer conotação pejorativa.

Se falamos em "baixa linguagem", é porque as práticas artísticas em espaços abertos recorrem seguidamente a formas de linguagem distintas das do fenômeno teatral em espaços fechados. Ora - e não é preciso desenvolver esse ponto -, o fenômeno teatral realizado nos espaços fechados se funda sobre "a linguagem do espetáculo [que] é constituído por signos da produção reinante, que são ao mesmo tempo a finalidade última dessa produção" (Debord, 1992, p. 5) ${ }^{23}$.

Antes de nos aprofundarmos no assunto, "baixa linguagem" serve para nos referirmos a uma organização vertical do espaço societal que privilegia formas visíveis, nas quais ela

22 (Benjamin, 2000, p. 21). Benjamin cita uma expressão de Alfredo Niceforo, autor de Le Génie de l'argot. Essai sur les langages spéciaux, les argots et les parlers magiques. A "baixa linguagem" benjaminiana não tem nada a ver com o "discurso do alto" ao qual ele se opunha, como explicou Jacques Rancière em La Parole ouvrière.

23 Dentre os elementos que compõem essa linguagem, podemos citar: o teatro de texto (de caráter repertorial e patrimonial), a arquitetura dos edifícios teatrais, os componentes cênicos do espetáculo, as convenções teatrais e sociais, etc., que obedecem a uma lógica de identificação do fenômeno teatral num espaço social compartimentado, de organização estratégica sócio-econômica, refletindo assim uma ordem política e ideológica. materializa e reivindica como elementos próprios de uma sociedade. Apesar da configuração vertical que, por seu lado, sempre corresponde a uma ideia de visível, de centralidade, de estabilidade, a isso que ela faz repercutir... Há também outras formas invisíveis, marginais, frágeis, mais pobres, o que estabelece uma diferença entre "a base e o topo"...

Por "baixa linguagem" designamos portanto tudo o que, estando no espaço societal, constitui "[...] a floresta dos desprezados urbanos e humanos [...]" (Maurice, 2010) ${ }^{24}$ o qual, tomando uma fórmula do arquiteto da área do urbanismo Patrick Bouchain ${ }^{25}$, pode representar "uma questão social, econômica, mas também estética".

Com efeito, prolongando o raciocínio de Bouchain, os espaços desprezados e residuais podem ser considerados como laboratórios a partir dos quais é possível de se imaginar políticas alternativas, uma vez que eles se encontram fora da lógica de mercado - pelo menos até que a ordem estabeleça que esses espaços sejam desapropriados ou interditados às comunidades que promovem práticas artísticas alternativas.

Ora, são inúmeros os espaços desprezados e residuais existentes numa sociedade que, regida pela lógica do mercado do espetácu-

24 Encontra-se num artigo destinado às reflexões de Patrick Bouchain. Na linguagem utilizada pelos cenotécnicos e intelectuais do espaço, um espaço "desprezado" consiste num lugar que não possui função, o que o faz seguidamente ser abandonado. Bouchain denominou de "o impensado da cidade".

25 Patrick Bouchain percebe sua prática de arquiteto como um "trabalho de encenador", considerando que "a arquitetura é política e que ela deve responder à preocupação de interesse geral" (Bouchain, 2005). Ele é um pioneiro na transformação de locais industriais em espaços culturais (como $\mathrm{La}$ Friche Belle de Mai, em Marselha...). Entre 1988-1995, como conselheiro do antigo Ministro da Cultura da França (Jacques Lang), Bouchain procurava articular projeto urbano e população, levando em conta o preceito Alta Qualidade Humana (H.Q.H.: Haute qualité humaine). 
lo, concentrou, isolou e organizou os espaços destinados ao fenômeno teatral. Esses espaços correspondem a todos os territórios que não foram validados pelos guardas do espetacular e pela polícia estética: ruas, praças, pontes, terrenos baldios, mercados, largos, jardins públicos, paradas de ônibus, etc.

Diante de lugares atribuídos ao fenômeno teatral, de distâncias que organizam os deslocamentos no espaço urbano, de "cadastros imobiliários" funcionais, de sinalizações que indicam os itinerários, organizam a informação, distribuem as concentrações de população e conduzem a movimentação... Diante desse contexto, as práticas artísticas alternativas fazem expandir o espaço ${ }^{26}$, bem como o desmembram. Ou ainda, mais fundamentadamente, elas criam situações, inventam espaçamentos, reduzem a distância entre a prática artística e os indivíduos que preenchem o espaço, ao ponto de suscitarem a seguinte idéia: se o indivíduo habita o espaço, é porque o espaço está dentro dele.

No que concerne a isso, Martin Heidegger, na sua conferência intitulada Construir, Habitar, Pensar por ocasião da Segunda Reunião de Darmstadt em 1955 sobre "o homem e o espaço", a separação entre eles se mostra como algo inadmissível. Tratando da relação que une indivíduo e espaço, o filósofo explicou que "o espaço não é algo que se opõe ao homem. Não é objeto exterior, nem experiência limite. Não existem indivíduos e, além deles, espaço" (Heidgger, 1980, p. 186).

Esta nuance, que serve para questionar a essência funcional que rege a organização e

26 Gostaríamos de desenvolver igualmente em nossa análise sobre o espaço uma reflexão sobre o tempo e a temporalidade das práticas artísticas alternativas, especialmente a maneira como elas rompem com a convenção de "noite de apresentação", entre outros. racionalização do espaço, confere às práticas artísticas um interesse adicional.

Elas podem ser tidas como práticas "rebeldes" ou manifestações discordantes porque operam através de um princípio diferente. Ou seja, em meio aos "não-lugares" oriundos da ordem vigente, elas retomam a lógica de divisão privilegiada; elas renovam o vínculo funcional com o espaço e com a atribuição-articulação de um lugar normalmente limitado a uma função; de igual forma, elas regeneram as formas estéticas do fenômeno teatral.

Em suma, as práticas artísticas alternativas corrigem um espaço societal repleto de insuficiências, onde a noção de "recorte funcional da cidade" substituiu a de espaço e a de funcionalidade prevalece sobre a idéia de habitat no sentido heideggeriano: "Os mortais são' quer dizer: habitam, eles se mantêm de uma ponta a outra dos espaços, do fato deles terem permanecido entre as coisas e os lugares" (Heidgger, 1980, p. 187). Por isso, tais práticas que se deslocam em liberdade possuem em ligação direta com a idéia de "mundo em comum"; elas nos lembram o essencial de "estar junto".

Sendo assim, elas se configuram efetivamente como práticas de resistência, as quais foram descritas por René Char: "O mundo contemporâneo já nos tirou o diálogo, a liberdade, a esperança, as diversões e a felicidade. Ele se prepara para ir até o coração de nossa vida a fim de apagar a última centelha, aquele do encontro" (Char, 1971, p. 35).

É o caso, por exemplo, do trabalho realizado em 2013 pelo grupo Falos \& Stercus, sob a direção de Marcelo Restori, Ilha dos amores, um dialogo sensual com a cidade, que nos dá diversos indícios sobre a questão da necessidade do encontro. 
Um grupo de performers (é assim que eles se designam) invade a "via pública" situada às margens do Arroio Dilúvio (um canal poluído); nela há também uma ponte ${ }^{27}$ pela qual o trânsito de veículos se desacelera em virtude do ato artístico. Em meio a gritos, cantos, movimentos coreográficos, nudez parcialmente exposta - o que chama a atenção dos transeuntes à distância -, se estabelece um encontro de outra natureza.

Em consequência, alguma coisa se torna mais lenta, como um momento em suspensão. Algo que altera o cotidiano sem, no entanto, fazê-lo desaparecer. Algo que se soma ao tempo, à paisagem, ao gesto... e ao espaço público. E a ordem pública, enfim, vem a ser deposta de seu domínio habitual sobre o movimento, sobre a organização do espaço e a distribuição dos indivíduos nele, sobre as línguas faladas, sobre a maneira como as pessoas se vêem e se escutam...

E então se expõe um ritmo diferente, uma linguagem diferente, um gesto diferente, uma proximidade diferente nesse espaço residual tomado pelos performers... De repente, algo de imprevisível se sucede no espaço residual. Entre todos os momentos em que performers e transeuntes se misturaram, nos focaremos num só incidente a fim de analisá-lo.

Um pai, com uma criança em seus braços, se aproxima de uma performer grávida. A criança, então, coloca sua mão sobre o ventre dela. Em seguida, iniciam uma conversa fugaz, de caráter não comunicacional, impossível de ser compreendida por terceiros. Essa situação ocorrida durante a performance (a qual, diga-se de passagem, contém muitos outros

27 Por conta de não sabermos o motivo exato pelo qual eles escolheram esse local para realizarem seu ato artístico, lembraremos das palavras de Heidegger, "a ponte reuni" (Heidgger, 1980, p. 181). elementos a serem analisados) poderia prontamente fazer com que o leitor, ao constatar seu caráter estratégico, proferisse a observação irônica "humano, muito humano". Por isso, ressaltamos que não é nosso objetivo tratar do "valor humano" contido nele, mas sim o modo como esse imprevisto envolve estruturalmente uma questão ao mesmo tempo antropológica e estética.

Recorrendo a tal exemplo, poderíamos admitir que o fenômeno teatral (presença de um ato artístico no espaço aberto), ao desenvolver sua própria dinâmica estética através da articulação com os elementos que compõe o espaço urbano (arquitetura, transeuntes, movimentações, polícia, regras do espaço público), produz um fenômeno de hibridização entre dois mundos. Estes, por sua vez, se encontram e se contaminam para formar um terceiro que, dependendo, pode legitimar o propósito de Heidegger e/ou nos situar num entusiasmo tido muitas vezes de utópico - uma vez que a fábrica do comum, o mundo em comum e o estar juntos são, assim, reais e reconhecíveis, via gesto partilhado (conforme a situação descrita anteriormente).

Se o teatro que privilegia o sistema econômico-político da ordem estabelecida tem como perspectiva instaurar uma "comunidade sensível" (expressão simplista que designa a produção de uma emoção a fim de conversão do público), a das práticas artísticas alternativas, calcadas num ecletismo de ruptura, parece descobrir a via que leva ao aparecimento de uma "comunidade sem comunidade".

Talvez seja por isso que, ao contrário das formas teatrais representativas da ordem vigente que se apóiam no efeito de espelho, onde o "tudo o que era diretamente vivencia- 
do se afastou numa representação"28 (Debord, 1992 , p. 3) faz com que o espectador tome o momento do ato artístico como um tempo e objeto exteriores a ele (Ihe remetendo a uma relação de consumismo), no fenômeno teatral nômade a prática artística não se efetiva através de uma imagem secundária (no sentido de reflexo, de imagem duplicada), mas sim do contato direto com a sociedade, sua vitalidade e seu movimento.

Logo, podemos tirar um ensinamento disso tudo.

Se, de um ponto de vista puramente estético, as diferentes práticas artísticas ou os fenômenos teatrais são complementares, sejam elas (dizendo simplesmente) realizadas nos espaços abertos e fechados ${ }^{29}$, o que as distingue é a representação que elas fazem do comum, a imagem que elas produzem disso e o proveito que o político pode tirar disso tudo. Que fique esclarecido, não há nada que as opõem diretamente.

Em compensação, como comenta Giorgio Agamben a propósito de $A$ Sociedade do Espetáculo de Guy Debord, reiterando a "implacável lucidez do diagnóstico":

a economia de mercado [...] após ter falsificado o conjunto da produção, pode agora manipular a percepção coletiva e se apoderar da memória e da comunicação social, para transformá-las numa única mercadoria espetacular, onde tudo pode ser colocado em questão, exceto o espetáculo mesmo que, em si, não diz outra coisa senão: 'O que aparece é bom, e o que é bom

28 Guy Debord fez uma crítica radical a tal prática, declarando que "[...] o espetáculo que inverte o real é efetivamente um produto [...]" (Debord, 1992, p. 6).

29 N. da T: aqui o autor utiliza as definições "dans les murs" (literalmente, "dentro dos muros"/ "dentro das paredes") para designar as práticas ocorridas em espaços fechados e "hors les murs" (o contrário: "fora dos muros") para descrever as que se passam nos espaços abertos. aparece' (Agamben, 1990, p. 81).

Desse modo, o surgimento de outro tipo de imagem via práticas artísticas alternativas resulta numa infração, em razão de que a arte é afastada do desejo de consumo. Aliás, desejo que se difundiu à medida que o mercado do espetacular se desenvolveu fabricando um "pensamento gorduroso" (Baudrillard, 2011, p. 37) , o $^{30}$ qual é, na verdade, um "não-pensamento". Ora, o que sempre esteve em jogo é a "memória", a comunicação entre as pessoas da sociedade, etc.

O que se atinge são um sistema e sua imagem, mais especificamente a imagem de um sistema responsável por formar à revelia indivíduos que constituam a "comunidade", uma comunidade estrangeira a si própria. O que se atinge é, em suma, a comunicação de um modelo representativo que revela ser apenas um modelo ideológico exclusivo. $O$ desenvolvimento das práticas artísticas alternativas equivale a uma "suspensão de juízo da comunicação": uma interrupção da comunicação com a ordem vigente.

$E$ é nesse ponto que podemos introduzir a questão da linguagem, precisamente a linguagem como espaço, já que "no espetáculo, é nossa própria natureza lingüística que avança de modo invertido na nossa direção" (Agamben, 1990, p. 82). Compreendemos aqui o espetáculo (Agamben, influenciado por Debord, designa a palavra "espetáculo" tal qual "produto") como algo que nos priva e mutila não somente do espaço, mas também da experiência da linguagem com nós-mesmos.

O que entendemos por "linguagem enquanto espaço"? O que pretendemos com tal afirmação?

30 Para Baudrillard, esta expressão designa as mentes cheias e cansadas. 
Antes de tudo, é necessário ressaltarmos que não nos referimos somente às formas discursivas quando falamos em "linguagem".

Se podemos prosseguir na ideia de que linguagem é espaço, é porque o espaço se trata de um elemento que faz parte do político e da política. Quanto a isto, Mikhail Bakhtin afirmara que: "Cada palavra, nós o sabemos, se apresenta como uma arena em miniatura onde se entrecruzam e lutam os acentos sociais com orientação contraditória. A palavra se revela, na boca do indivíduo, como o produto da interação viva das forças sociais [...]" (Bakhtin, 1977, p. 67). Lembremos também da análise de Herbert Marcus - "[...] a sintaxe, a gramática, o vocabulário são atos morais e políticos" (Marcuse, 1968, p. 220) - e de Hannah Arendt - "[...] desde que o papel da linguagem é posta em jogo, o problema se torna político por definição" (Arendt, 2012, p. 61).

Ou seja, a linguagem é um território legítimo de conflitos, de conquistas e uma questão que, para a ordem, consiste num meio de instaurar seu controle. Já para as práticas artísticas alternativas (conforme o capítulo "A baixa linguagem"), ela permite fazer a experiência em meio a um processo de reescritura do espaço. Essa constatação a respeito da arte e do fenômeno teatral nos leva à análise de Herbert Marcuse, que faz eco ao ponto de vista de Roland Barthes quanto à utilização e organização da linguagem no espaço societal, bem como de sua ligação para com as artes.

Num artigo intitulado "A Face Barroca", (Barthes, 1984, pp. 283-285) mostrava que "a escrita pode fazer tudo de uma língua, e em primeiro lugar torná-la livre" (Ibid., p. 284). Seu estudo, a respeito das formas literárias (e teatrais) submetidas a limitações de formas e estilos, o levou a versar sobre "verbalismo" - do qual recebe "mais destaque a poesia" (Ibid., p. 285). Barthes seguiu sua reflexão reiterando que a bela obra de arte, a arte bem feita "transforma a escrita em aula" (Ibid., p. 285) reduzindo-a em "mercadoria útil para economia humana" (p. 285) ${ }^{31}$, enquanto que o verbalismo ou a poesia gera "a energia da fala" (Ibid., p. 285). Num desdobramento dessa análise, citando em diversos momentos o autor de $\mathrm{O}$ rumor da língua por pactuar de sua perspectiva, Herbert Marcuse mostra como a linguagem, organizada no campo social por seus agentes, é destruída e empobrecida por um conjunto de procedimentos que a afastam de todas "tensões". Consequentemente, o material lingüístico é modulado, "talhado", organizado conforme o papel que lhe é atribuído, sendo por isso privado de todo espaço que poderia gerar uma "crítica". Desse modo, sob um princípio de rejeição aos "elementos fora dos conformes" (Marcuse, 1968, pp. 109-144), a linguagem se torna operacional, de uso funcional, em suma, uma "linguagem harmonizada que é fundamentalmente anti-crítica e anti-dialética" (Marcuse, 1968, p. 121). Ao longo de seu raciocínio sobre os efeitos da linguagem funcional, Marcuse demonstra ainda que desta deriva um caráter "radicalmente anti-histórico", a fim de que se afaste dos "conteúdos subversivos da memória" (Ibid., 1968, p. 123).

Em outras palavras, as determinações operacionais que se manifestam na linguagem mutilam a "forma de mediação" (Ibid., 1968, p. $123)^{32}$ que a induz e que é uma de suas ca-

31 Essa ideia de característica comercial é recorrente do início ao fim do artigo La Face baroque. Em dado momento, ele afirma que: "Para os franceses, é importante o 'alguma coisa para dizer', o que se designa frequentemente por uma palavra foneticamente ambígua, monetária, comercial e literária: o fundo (ou fundos)" (Barthes, 1984, p. 283).

32 A fim de aprofundar esse raciocínio, Marcuse cita diversos autores, como Adorno: "a sociedade burguesa em progres- 
racterísticas principais. Assim, a linguagem trazida para a "linguagem fechada" 33 se apóia num princípio recorrente a sua utilização que é o de embaralhar a memória, fazendo com que o indivíduo se torne familiarizado a essa estranheza em relação ao poder e à força da linguagem. Desse modo, o conjunto dos elementos do campo social (o que Louis Althusser ${ }^{34}$ define de A.R.E. e de A.I.E.) trabalha com um mesmo objetivo e tentativa, onde "o homem é treinado a esquecer" sua capacidade crítica e seu livre exercício por meio de uma linguagem sem-tensão.

O intercruzamento das perspectivas de Barthes e Marcuse nos auxilia a esclarecer a relação que o teatro privilegiado pela ordem vigente mantém com a linguagem fechada.

Apesar disso, ao longo da história do teatro, algumas vozes se levantaram contra essa submissão que petrificou a linguagem teatral numa ordem poética e estética - as quais nada

so liquida a memória, o tempo, a lembrança, como resíduos irracionais" (Adorno apud Marcuse, 1968, p. 12). A citação original de Adorno pode ser encontrada em "Wes bedeutet Aufarbeitung des Vergangenheit ?", in Bericht über die Erziehertkonferenz am 6 und 7 November in Wiesbaden, Francfort, 1960, p. 14.

33 Se é preciso definir a "linguagem fechada", lembremos da definição de Herbert Marcuse: "A linguagem fechada não demonstra, não explica, mas sim comunica a decisão, sentencia, ordena" (1968, p. 126).

34 Louis Althusser descreve, dentre outros temas, que a história do espaço social está vinculada a uma luta de classes organizada entre o pólo dominante e o pólo dominado. Por estarem a serviço da classe dominante, a A.R.E (aparelho repressivo do Estado) e a A.I.E. (aparelho ideológico do Estado) permitem que a ordem social seja organizada e legitimada, ou através de agentes violentos legítimos (polícia, tribunais, exércitos, etc.) que fazem parte da A.R.E., ou através do desenvolvimento de uma rede da A.I.E., a qual se caracteriza por também ser coercitiva, mas cuja violência é ideológica. Mais detalhadamente, esta última exerce influência sobre as mentalidades e a representação que fazemos de nós-mesmos. Dentre os membros da A.I.E, podemos considerar, por exemplo, as áreas das Letras e Belas-Artes. Por fim, salientamos que os da A.R.E integram a organização pública, enquanto que os da A.I.E. procedem de uma gestão que pode ser tanto pública quanto privada. mais eram que uma extensão da ordem política. Por exemplo, há essa afirmação reverberante de Artaud (1964):

A questão que se coloca é de permi-
tir ao teatro de reencontrar sua verda-
deira linguagem, linguagem espacial,
linguagem de gestos, de atitudes, de
expressões e de mímicas, linguagem
de gritos e onomatopéias [...] que te--
rão tanta importância intelectual e de
significação sensível quanto a lingua-
gem das palavras [...]"35. [Ou ainda]: A
questão do teatro é questionar qual é
a linguagem pertencente somente ao
teatro [...]" (Artaud, 1964, p. 15). E por
último: "uma concepção européia do
teatro quer que o teatro seja confundi-
do com o texto [...]. Diante disso, nos
parece que [...] a encenação se torne
uma linguagem particular [...]. Isso faz
com que a linguagem falada seja ime-
diatamente questionada [...]" (Artaud,
1964, p. 16-17).

Além de Artaud, Jerzy Grotowski abriu o teatro a outros horizontes, como podemos perceber num trecho de sua conferência sobre "O Teatro de hoje em busca do rito" 36 em 15 de outubro de 1968:

Eu tinha uma determinada imagem do teatro possível, imagem que, num certo sentido, estava formada em oposição ao teatro existente, esse teatro excessivamente cultural no senso convencional, um produto do encontro entre pessoas cultivadas: pessoas que trabalham com palavras, falas, gestos, cenários, iluminação, etc., e consequentemente outras pessoas bem cultivadas, que sabem que se deve ir ao teatro porque é uma espécie de obrigação moral ou cultural. No final das contas, todos saem muito cultiva-

350 volume tem como subtítulo Autour du théâtre et son double, et des Cenci. A edição coloca duas vezes essa passagem (antes e depois da representação de Os Cenci). O primeiro, com o título Le théâtre que je vais fonder (pp. 35-37); o segundo numa carta ao Monsieur Van Cauclert, datada em 6 de julho de 1932 (p. 101).

36 Publicado em Journal France-Pologne peuples amis, n. 2829, hiver 1968. 
dos desses encontros, mas nada de essencial pôde se passar entre elas. Cada um resta prisioneiro de um certo tipo de convenção, de pensamento e de ideias relativas ao teatro. (Grotowski, 1968, p. 14).

Isto é, trata-se de uma perspectiva que deve permitir ao teatro de entrar no "[...] caminho em direção ao teatro vivo [...]" (Grotowski, 1968, p. 14), para que dessa forma ele se livre do "teatro banal" (Grotowski, 1968, p. 15).

É visível que, embora as políticas culturais tenham se intrometido aqui e lá, gerando "palavras de ordem"37 que tornaram a prática teatral uma engrenagem das mais complexas do tecido urbano, tem se afirmado ao mesmo tempo uma consciência de linguagem teatral independente das questões de retórica política (a qual atenta para uma estética relacional e uma estratégia de comunicação).

Com efeito, as práticas artísticas alternativas (tais qual o "verbalismo") resistem à "linguagem fechada", já que ao regenerarem o fenômeno teatral, elas respondem tanto à Marcuse quanto à Barthes quando este escreveu sobre a linguagem teatral: "O que é o teatralizar? Não é ornamentar a representação, mas sim ilimitar a linguagem [...]" (Barthes, 1971, p. 10).

Em vista disso tudo e evocando Barthes, me parece que a singularidade dessas práticas é a de fazer existir um "gesto barroco".

37 Essas do chamado "Teatro popular", dentre outros, que continuam a alimentar as políticas culturais.

\section{O gesto barroco}

Se, de acordo com Jean-François Lyotard,

o tempo não se deteve a notar a captura e o apagamento dos fluxos libidinosos numa ordem cuja a representação e suas divisões associáveis ou dissociáveis são, seriam a última palavra, pois essa captura e essa supressão são o capitalismo, no entanto o tempo serviu e incentivou sua divagação errante em todas as superfícies e fendas imediatas, cheias de corpos, de história, de terra, de linguagem (Lyotard, 1994, p. 23),

tais práticas alternativas são esse "tempo vindo". "Tempo vindo" que se manifesta pela instauração de dispositivos que rompem com os protocolos do teatro e as expectativas da comunidade de espectadores, sob a forma, a priori, de uma desordem estética. Dessa forma, dá-se uma "virada estética" que é implicitamente também uma "virada política".

É necessário reconhecermos e identificarmos através dessas experiências teatrais uma "resposta" e uma análise aos modos de "[...] controle-repressão e controle-estímulo [...]" (Foucault, 2001, p. 1623) desempenhadas pelo sistema liberal, o qual organiza conjuntamente a produção e a recepção das obras artísticas via industrialização cultural. Em consequência, de um lado há a organização do gosto; de outro, uma economia (organização do custo) fundada no princípio de "conquista do público".

Indústria que tende a conservar "sua própria linguagem com sua sintaxe e seu vocabulário próprios" (Horkheimer; Adorno, 1974, p. 137), ao ponto de afastar a diversidade dos modelos.

Indústria forte de tal êxito, constatável por meio de um efeito de hipnose que se traduz num movimento de concentração (denunciado primeiramente por Adorno \& Horkheimer, em 
seguida por Habermas), onde os comportamentos e as reações levam a "[...] fazer como todo mundo, participar da agitação, ficar na fila [...]" (Adorno, 2003, p. 160).

Indústria que se observa como se colocasse uma "cortina ideológica" (Horkheimer; Adorno, 1974 , p. 18). Através dessas formas que integram a comunicação da ordem vigente - em que "[...] nenhum pensamento é imune contra os riscos da comunicação [...]" (Adorno, 2003, p. 26) -, o controle exercido no espaço societal (isto é, na sua memória, sua linguagem, sua estética...) transforma a paisagem artística; a tal ponto, que o fenômeno teatral tem somente a oferecer espetáculos onde o público pode "ver em cena o que está na cabeça e no corpo [...] para se reconhecer [...] na esperança de poder dizer ao final: 'é bom isso' [...] primeira satisfação"' (Althusser, 1997, p. 554).

Assim, as práticas artísticas alternativas fazem surgir o gesto barroco no espaço.

Mesmo que a ordem liberal não cesse de insistir nesse caráter de comunhão, de reunião de pessoas, conforme havia revelado Jean-François Lyotard ("Aos estudantes, aos artistas, aos escritores, aos eruditos, o capitalismo ordenava: sejam inteligentes, sejam inventivos, suas ideias são minha mercadoria no futuro"), emerge-se um gesto ligado "mais à imaginação que ao mercado" pronto "a experimentar sem limites" (Lyotard, 1994, p. 17). Reverberando e se apropriando desse princípio de desregulação que é próprio da ideologia liberal, os grupos e coletivos o aplicam à lingüística e à estética, sob o risco de enfrentarem a fúria do arsenal judiciário e jurídico: prisão, intimidação, processo, detenção, expulsão ${ }^{38}$, exílio...

38 A título de exemplo, a expulsão dos grupos do Hospital Psiquiátrico São Pedro, em Porto Alegre; dentre eles, está o Falos \& Stercus. Um dos pavilhões do hospital servia como sede para diversos grupos de artes cênicas, onde havia salas
A essência do gesto barroco é a de fazer existir no espaço societal "uma ordem selvagem" (Dorléac, 2004). Em alguma medida, trata-se de uma reação física, orgânica, lingüística à tentativa de comunicação, à efetivação da linguagem pela comunicação, ao desaparecimento da linguagem morta de cansaço.

Não se restringindo a um ganho de liberdade, dele surge essa possibilidade da qual a ordem vigente se apropriou. Acarreta-se, então, um conflito entre a linguagem dramática (mesmo durante a representação) e a "dramatização da linguagem", ou ainda um questionamento a respeito dos elementos do fenômeno teatral pois, conforme analisou Gilles Deleuze, a "obra de arte não é um instrumento de comunicação. A obra de arte não tem nada a ver com comunicação. A obra de arte não contém, estritamente, a mínima informação. Em compensação, existe uma afinidade fundamental entre obra de arte e ato de resistência" (Deleuze, 2003, p. 300).

O gesto barroco - o que alguns identificarão de "virada performativa" - se refere a uma conduta "de inscrição" (Lyotard, 1994, p. 23) que, conforme Lyotard, designa uma ruptura definitiva com a representação clássica e tradicional.

"Inscrição" no espaço que serve para testar a imaginação receptiva do indivíduo, bem como o convida a sentir o gosto da imaginação criativa - a do artista e a de si próprio. Por consequência, o gesto barroco é o fermento para a suspensão de juízo - a interrupção da capacidade de julgamento - que torna o indivíduo, anteriormente resistente à reflexão e à reaparição da linguagem, dessa vez disposto a

de ensaio e depósitos de cenário. Eles mantinham uma atividade artística junto aos internos do Hospital, já que este é um centro de internação e tratamento. 
fazer a experiência da linguagem e da reflexão. Se por ventura esse gesto não é estranho à produção de significados e sentidos (aludindo aqui a logos) nas outras modalidades estéticas e lingüísticas que as produzidas pela representação, é porque ele é essencialmente ligado a épos: surgimento de intensidades nascidas a partir do encontro entre o artista e sua testemunha.

Talvez aqui se esboce uma construção partilhada e restabelecida; um "bem comum" que produz a ideia de "mundo em comum"; um momento onde o gesto barroco que é, sem dúvidas, uma rebelião, se exprime por meio do levante indivíduo, de seu gesto fugaz e anônimo; um instante onde a conquista do espaço envolve uma prática artística e um indivíduo, a fim de que o espaço se torne o lugar da consciência nítida - através da qual a memória, que está sujeita a se lembrar o que é viver a sociedade, volte a vislumbrar que "[...] a principal obra de arte com a qual é preciso se preocupar, a zona maior onde se deve aplicar os valores estéticos, é em si mesmo, sua própria vida, sua existência [...]" (Foucault, 2001, p. 1221).

Desse modo, na rua, junto aos invisíveis e desprezados (que são um reflexo de todos), aos "pequenos"39, em direção ao fim dessa figura que se mantém sob cuidados, desse ser menor... O gesto barroco permite considerarmos o fim disso que chamamos de "espectador": é quando a arte se fundirá à vida, a sua fluidez.

Continuando o diálogo com nosso amigo ${ }^{40}$,

39 Referência ao posfácio de Minima Moralia, "a escolha do pequeno", escrito por Miguel Abensour. Dentre outras passagens, há essa: "investir contra a dominação do monumental, o pequeno, aprender a redescobrir a singularidade, no mesmo momento em que ela é rejeitada" (ibid., p. 340).

40 Diálogo com meu "gêmeo" Christophe Bident, que analisou o espetáculo BR3, de Antônio Araujo. Para leitura: Christophe Bident, "Le théâtre traversé ", Théâtre/Public n²21. États esperamos que o teatro expandido (o qual é somente o deslocamento do teatro para fora do teatro, sem trazer prejuízo ao princípio estruturante da "cena reservada") seja só uma etapa (já que ela mantém a divisão arte/espectador, transmissão de aula, distância e diferença, etc.) antes do grande desarranjo - como o que falamos sobre a "grande noite" - nos libertar desse sub-indivíduo que é o espectador, o qual se mantém à distância de sua vida, ocupado a olhar sua vida, fixo pelo olhar, no olhar, mais que viver... Assim será a verdadeira revolução, o caos ou mais simplesmente o retorno do movimento que é a subjetivação, esse estado de "pensando o indivíduo que se pensa" do qual trataram Deleuze e Foucault ${ }^{41}$.

Em suma, um indivíduo que fugiria da "massa" e da "compacidade"42 das salas de espetáculo que estão, sempre, à sombra das sociedades de controle.

[...] o poeta é a parte que resiste aos projetos calculados (Char, 1971, p. 33).

de la scène actuelle 2014-2015, juillet-septembre 2016.

41 Poderíamos citar novamente Foucault, que evidencia esse princípio de subjetivação: "o que me impressiona é o fato que em nossa sociedade a arte se tornou alguma coisa que só mantém relação com os objetos, e não com os indivíduos ou com a vida; além do mais, a arte é uma área especializada feita por especialistas que são os artistas. Mas a vida de todo indivíduo não poderia se tornar também uma obra de arte? Por que uma lâmpada ou uma casa são os objetos da arte, mas não as nossas vidas?" (Foucault, 2001, p. 1211).

42 O termo "massa" foi emprestado de Elias Canetti. Foi a partir da leitura de Canetti que Miguel Abensour elabora o de "compacité" (Abensour, 2013, p. 32-33). 
Referências

ABENSOUR, Miguel. De la compacité, architectures et régimes totalitaires. Paris, Sens\&Tonka, 2013.

ADORNO, Theodor. Minima Moralia, Réflexions sur la vie mutilée. Paris: Bibliothèque Payot, 2003.

AGAMBEN, Giorgio. La Communauté qui vient, théorie de la singularité quelconque. Paris, Seuil, 1990.

ALTHUSSER, Louis. Ecrits philosophiques et politiques, v. 2, Paris, Stock, 1997.

ARENDT, Hannah. L'Humaine condition, Paris, Gallimard, 2012.

ARTAUD, Antonin. OEuvres complètes, v. 5, Paris, Gallimard, 1964.

BAKHTINE, Mikhail. Le marxisme et la philosophie du langage. Tradutora: Marina Ya guello. Paris: Minuit, 1977.

BALANDIER, Georges. Le Désordre, éloge $d u$ mouvement. Paris: Fayard, 1988.

BARTHES, Roland. Le Bruissement de la langue: essais critiques IV. [Paris]: Seuil, 1984.

BARTHES, Roland. Sade, Fourier, Loyola. Paris: Seuil, 1971.

BAUDRILLARD, Jean. D'un fragment l'autre. Paris: Albin Michel, 2011.
BENJAMIN, Walter. Problèmes de sociologie du langage. In: OEuvres III. Paris: Gallimard, 2000.

BOUCHAIN, Patrick. In: Patrick Bouchain, pour faire avancer l'architecture, il faut de l'audace, propos recueillis par Michèle Leloup à l'Express. 13 jun. 2005.

CHAR, René, Recherche de la base et du sommet. Paris: Gallimard, 1971.

CLASTRES, Pierre, Une Société contre l'État, Recherche d'anthropologie politique. Paris: Minuit, 1974.

DEBORD, Guy. La Société du spectacle. Paris: Gallimard, 1992.

DELEUZE, Gilles. Deux Régimes de fous, textes et entretiens 1975-1995. Paris: Minuit, 2003.

DELEUZE, Gilles. Pourparlers. Paris: Minuit, 1990.

DELEUZE, Gilles; GUATTARI, Felix. Mille Plateaux: Paris. Minuit, 1980.

DORLEAC, Laurence Bertrand. L'Ordre sauvage: Paris: Gallimard, 2004.

DORT, Bernard. Lecture de Brecht. Paris: Seuil, 1960.

FOUCAULT, Michel. Dits et écrits 1, 1954-1975. Paris: Gallimard, 2001.

GALEANO, Eduardo. Les Veines ouvertes d’Amérique Latine. Paris: Plon, 1981. 
GROTOWSKI, Jerzy. Le Théâtre d'aujourd'hui à la Recherche du rite. Journal France-Pologne peuples amis, n. 28-29, inverno 1968.

HEIDEGGER, Martin. Bâtir Habiter Penser. Essais et conférences. Paris: Gallimard, 1980.

HORKHEIMER, Max; ADORNO, Theodor. La Dialectique de la raison. Paris: Gallimard, 1974.

KOUNELLIS, Jannis, In: Après la scénographie », entretien dirigé par Guido Boursier, Italo Moscati et Marisa Rusconi, in Sipario, $\mathrm{n}^{\circ} 276$, abril 1969.

LYOTARD, Jean-François. Des Dispositifs pulsionnels. Paris: Galilée, 1994.

LYOTARD, Jean-François. Textes dispersé I: esthétique et théorie de l'art. Bélgica: Leuven University Press, 2012.

MARCUSE, Herbert. L'Homme unidimensionnel, essai sur l'idéologie de la société industrielle avancée. Paris: Minuit, 1968.

MAURICE, Guillaume. L'archipel des délaissés. Critique, n. 757-758, p. 542-555, Paris, Minuit, 2010.

NEGRI, Antonio, Du Retour. Abécédaire biopolitique. Entretiens avec Anne Dufourmontelle. Paris: Calmann-Lévy, 2002.

NIETZSCHE, Friedrich. Le Gai savoir: aphorisme 109. Paris: Gallimard, 1982.

RANCIERE, Jacques, Malaise dans l'esthétique. Paris: Galilée, 2004.
SANTOS, Milton, La Nature de l'espace, technique et temps, raison et émotion. Paris: L'Harmattan, 1997.

STIEGLER, Bernard, De la misère symbolique. Paris: Galilée, 2004.

Recebido: 18/05/2017 Aprovado: 08/07/2017 